\title{
THE IMPACT OF BEAD DENSITY ON PAINT PAVEMENT MARKING RETROREFLECTIVITY
}

\author{
Guanghua Zhang \\ Ph.D. candidate \\ Department of Civil, Construction, and Environmental Engineering \\ North Carolina State University \\ Raleigh, NC 27606-7908 \\ Telephone: (919) 515-6456 Fax:(919) 515-7908 \\ Email: gzhang3@ncsu.edu \\ Joseph E. Hummer, Ph.D., P.E. \\ Professor \\ Department of Civil, Construction, and Environmental Engineering \\ North Carolina State University \\ Raleigh, NC 27606-7908 \\ Telephone: (919) 515-7733 Fax:(919) 515-7908 \\ Email: hummer@eos.ncsu.edu \\ William Rasdorf, Ph.D., P.E., F.ASCE \\ Professor \\ Department of Civil, Construction, and Environmental Engineering \\ North Carolina State University \\ Raleigh, NC 27606-7908 \\ Telephone: (919) 515-7637 Fax:(919) 515-7908 \\ Email: rasdorf@eos.ncsu.edu
}

March 2009

Word Count: 5,877

Figures: 11

Tables: 3 


\title{
THE IMPACT OF BEAD DENSITY ON \\ PAINT PAVEMENT MARKING RETROREFLECTIVITY
}

By

Guanghua Zhang, M.S., Joseph E. Hummer, Ph.D., P.E., and William Rasdorf, Ph.D., P.E., F.ASCE

\begin{abstract}
This paper addresses the impact of bead density on paint pavement marking retroreflectivity. The authors collected retroreflectivity data and glass bead images on 40 segments of two-lane highways. Bead density is defined as the surface percentage of glass beads exposed above the paint marking material. Numerous methods for determining bead density were considered and studied. A new approach, referred to as a computer-aided counting method, was developed and a bead density analysis program was written. The program was used to analyze 108 images to obtain a bead density value for each image.
\end{abstract}

A correlation study was conducted between pavement marking retroreflectivity and bead density. The findings of the study show that the normal range of glass bead density for older markings is 9-24 percent of the paint marking surface area. Furthermore, bead density values have a positive correlation with marking retroreflectivity readings; higher bead density leads to higher retroreflectivity. White paint markings have significantly higher retroreflectivity values than do yellow markings when the bead density values are the same.

Keywords: Pavement Marking, Retroreflectivity, Glass Beads, Bead Density, Image Analysis 
THE IMPACT OF BEAD DENSITY ON

PAINT PAVEMENT MARKING RETROREFLECTIVITY

By

Guanghua Zhang, M.S., Joseph E. Hummer, Ph.D., P.E., and William Rasdorf, Ph.D., P.E.,

$$
\text { F.ASCE }
$$

\author{
INTRODUCTION \\ LITERATURE REVIEW \\ RESEARCH OBJECTIVES \\ PAINTING METERIALS AND PROCESS \\ Glass Beads \\ Paint Marking Material \\ Paint Marking Application \\ METHODOLOGY
}

Field Data Collection

$\underline{\text { Site Selection and Layout }}$

$\underline{\text { Retroreflectivity Measurement }}$

Image Acquisition

Bead Density Determination

Counting - A Completely Manual Method

Automated Image Processing

Computer-Aided Counting - A Semi-automated Method

\title{
RESULTS
}

CONCLUSIONS

RECOMMENDATIONS

ACKNOWLEDGEMENT

RERERENCES

The outline is provided only for reviewer's convenience 


\section{THE IMPACT OF BEAD DENSITY ON PAINT PAVEMENT MARKING RETROREFLECTIVITY}

By

Guanghua Zhang, M.S., Joseph E. Hummer, Ph.D., P.E., and William Rasdorf, Ph.D., P.E., F.ASCE

\section{INTRODUCTION}

Pavement markings are considered to be traffic control devices having the function of controlling traffic and encouraging safe and efficient vehicle operation [AASHTO 2004]. The Manual on Uniform Traffic Devices for Streets and Highways (MUTCD) is the most important document guiding pavement marking use in the United States. It specifies where centerline, lane line, and edge line markings are to be provided based on the type of roadway, the width of the road, and the annual average daily traffic (AADT) [Federal Highway Administration (FHWA) 2003].

Water-based paint is currently the most commonly used pavement marking material. Paint is used on almost $60 \%$ of the total pavement marking mileages according to a survey conducted in 2000 [Migletz and Graham 2002]. However, in NC at the present time, water-based paint markings are reported to make up more than $80 \%$ of the total marking mileages [NCDOT 2008]. Other types of pavement marking material such as thermoplastics, epoxy, polyurea, and preformed plastics are also used. The primary focus of this paper is on paint pavement markings though the research method presented herein can also be applied to other types of marking materials.

During daytime, drivers discern pavement markings mainly by the color contrast between the marking and the pavement surface. Nighttime visibility, however, is a function of the luminous contrast between the pavement markings and the road surface, which is generally determined by the pavement marking retroreflectivity. Retroreflectivity is a term used to describe the amount of light returned back to a source, such as the amount of light from a vehicle's headlight that is reflected back towards the driver. The reflected light provides the driver with roadway information and enables a safer drive at night. Retroreflectivity is represented by a measure referred to as the coefficient of retroreflected luminance $\left(R_{L}\right)$, which is expressed in units of 
millicandelas per square meter per lux $\left(\mathrm{mcd} / \mathrm{m}^{2} / \mathrm{lux}\right)$ [ASTM, 2001]. The current ASTM standard requires that retroreflectometers use a 30-meter geometry [ASTM 2005]. This article discusses retroreflectivity of pavement markings and its relationship to the beads embedded in the markings.

Pavement marking retroreflectivity is achieved through the use of glass beads on the surface of, and partially embedded in, the paint. Auto headlights are reflected in all directions when illuminated on markings without beads, and only a small amount of light is reflected back to the driver. In contrast, a much greater quantity of light is reflected back to the driver if the marking contains glass beads. Using glass beads in a reflective binder, such as paint, to achieve nighttime retroreflectivity is now a world-wide accepted practice.

Pavement marking retroreflectivity values are intuitively thought to depend on the quantities and qualities of the glass beads in the markings. However, if a glass bead is fully embedded in the marking binding material, it will not reflect headlight back to the driver. Retroreflectivity is primarily achieved by the portion of the beads exposed above the paint. Traffic engineers generally believe that an optimum occurs when $40 \%$ of each bead is exposed above the marking and $60 \%$ is embedded in the marking. In this paper, we define the bead density as the surface percentage of glass beads that are exposed above the marking binding material.

This paper reports on the use of image processing techniques to measure the bead density of paint pavement markings. Additionally we are reporting on a correlation study between painted pavement marking bead density and retroreflectivity.

\section{LITERATURE REVIEW}

Much pavement marking research to this point has focused on modeling of marking retroreflectivity and on the performance and the safety effects of pavement markings. Few articles examine why and how retroreflectivity values degrade over time. This paper examines one degradation factor - bead density. 
We reviewed several studies that provide insight into degradation models to predict long term pavement marking performance. An early study by Dale reported that pavement marking service life was a function of the type of pavement, the volume of traffic, and the average snowfall per year if the materials were applied to a properly prepared surface using the recommended application procedure [Dale 1988]. Several types of degradation models such as logarithmic [Andrady 1997, Abboud and Bowman 2002], exponential [Perrin et. al. 1998], and linear regression models [Lee et. al. 1999, Sarasua et. al. 2003, Sitzabee 2008] were established based on the data collected in each of these studies.

The above mentioned studies have established that longitudinal pavement markings can reach the end of their service lives because of bead loss (resulting in poor retroreflectivity), loss of the marking material because of chipping and abrasion, color change of the marking, or loss of contrast between the base material of the marking and the pavement. Daytime and nighttime visibility are closely related because as a marking is chipped or abraded by traffic there typically is not only loss of marking material over time (which decreases the daytime visibility of the markings) but there is also a loss of beads (which results in a reduction in the nighttime retroreflectivity of the marking) [Migletz and Graham 2002].

Rich et. al. conducted a pioneering study of the impact of bead density on marking retroreflectivity [Rich et. al. 2002]. The study used a specialized digital camera (Spot RT) to collect high resolution glass bead images. The digital images were then converted into binary images. The binary images were analyzed to extract bead density values.

The Rich study found that the surface percentage of glass beads (bead density), glass weight percentage, and paint marking retroreflectivity variables were well correlated to each other [Rich et. al. 2002]. However, the work was preliminary and had three major shortcomings. First, the glass bead images used in that study were collected on roads with newly applied paint. The glass beads and the paint were in an initial perfect condition. There were no glass beads losses due to traffic wear, weather, or age. The elements on the images included both the glass beads and the background markings. However, pavement markings which have been worn by traffic normally show different patterns than newly applied smooth paint. In such markings there are numerous 
holes left in the paint as the glass beads are knocked out by wear and these were not accounted for in the Rich study. Also, the images used in the Rich study were taken from aluminum plates that were painted in the field and returned to the laboratory for evaluation [Rich et. al. 2002]. The images were not taken on real world pavement markings applied to asphalt. Finally, the details of the image processing procedure were not revealed in the available literature.

In another study conducted in Iowa, Mizera et. al. manually counted the number of glass beads in a 1 inch by 1 inch sample. Four samples were counted and an average value from four samples was calculated as the number of glass bead for the pavement marking line [Mizera et. al. 2009]. The objective of the Mizera study was to compare how many beads two bead guns dispense when operating at the same speed.

The goal of our study was to determine bead density, which was different from Mizera study. In a similar manual counting effort we found that the method cannot produce an accurate bead density value as we defined above. We describe the details of the manual count method in the Methodology Section of this paper and compare our results to Rich and Mizera studies.

\section{RESEARCH OBJECTIVES}

The first objective of this study was to find a way to measure the bead density of pavement markings in the field. The measurement method has two requirements. First, the method should be able to produce an accurate bead density. Second, the method should be easy to perform. It should also not involve many specialized tools so that other researchers or engineers can replicate the method. Thus, we explored a number of digital image processing techniques to see if we could determine glass bead density accurately and rapidly and which method met our two requirements.

The second research objective was to investigate the impact of bead density on paint pavement marking retroreflectivity. To do so we collected retroreflectivity data and glass bead images in the field. To achieve both research objectives we processed the digital images and performed a correlation analysis between the bead density and the marking retroreflectivity. 


\section{PAINTING MATERIALS AND PROCESS}

This section introduces the reader to various aspects of glass beads and paint marking materials. We also briefly discuss the paint marking application process.

\section{Glass Beads}

The glass bead refractive index, diameter, roundness, their embedment depth, and their density in the paint all have impacts on the retroreflectivity values of the pavement marking as a whole. The amount of retroreflected light depends on these parameters and on the type of the glass beads. This paper focuses on depth and density.

A bead refractive index is dictated by the chemical and physical makeup of the glass material [VDOT 2008]. AASHTO standard M247-07 requires glass beads to have a refractive index of 1.50-1.55 [AASHTO 2007]. Glass beads are recognized to provide their best retroreflection when about $40 \%$ of each bead is exposed above the marking and $60 \%$ is embedded in the marking. The Standard Specifications for Construction of Roads and Bridges on Federal Highway Projects (FP-03) specifies a glass bead application rate of $6 \mathrm{lb} / \mathrm{gal}$ or $12 \mathrm{lb} / \mathrm{gal}$ for waterborne paint depending on the type of glass bead used [FHWA 2003].

Five types of glass beads are defined in the FP-03. The classification of pavement marking glass beads into types is based on their gradation (size). The first two types of glass beads (I and II) are defined by an AASHTO standard and their gradations are shown in Table 1 [AASHTO 2007] as an example. The reader should recall that a smaller sieve size represents a larger hole and thus, a larger bead. Type I is referred to as a standard glass bead and type II is known as a uniform gradation glass bead [AASHTO 2007]. Types III, IV, and V glass beads are known as large glass beads. These are not shown here as they pass through a large group of sieve sizes (825). In this study, all the data were collected on markings containing Type I (standard) glass beads. But, note from Table 1 that each type classification of bead is comprised of beads of various sizes as specified in the table at the percentage levels shown. The fact that a bead type does not contain same size beads has a profound impact on bead density. 


\section{Paint Marking Material}

Paint is mainly composed of finely ground pigments that are mixed into a resin or binder system. Various ingredients and additives are incorporated to obtain certain desired properties. A liquid (water or solvent) is added to the mixture to produce a material that is pliable by application equipment [VDOT 2008]. Water-based paint is more environment friendly than solvent borne paint. Water-based paint is currently the most commonly used pavement marking material.

Paint markings are typically 15 to 25 mils ( 0.015 to 0.025 inch) in thickness when applied. Paint drying time depends on the thickness and its composition as defined in the paragraph above. As a rule of thumb, a paint truck speed of 10-12 mph will result in a paint thickness of 15-18 wet mils without beads. Glass beads are usually dropped (using a mechanical pressurized means) into the wet paint as the paint is applied to roads [NCDOT 2006].

\section{Paint Marking Application}

Paint marking thicknesses and glass bead application rates are specified in the FP-03. However, thickness and application rate are very hard to control in the field during the paint marking application process. The quality of the markings generally depends on the experience of the paint crew.

Immediately after application, paint crew technicians examine the paint surface glass beads with a magnifier. If the glass beads are found to be too dense or too sparse (determined by a superintendent via visual inspection), the technicians will adjust the pressure in the glass bead tank or the glass bead dispenser until they obtain a satisfactory glass bead density. This paint truck calibration process is conducted on a test road to ensure that the applied markings have good qualities as determined by visual inspection. In the field, the paint crew normally cleans the bead guns and adjusts the bead tank pressure every morning before the paint application.

Paint crews also calibrate the bead guns using a kit form the bead manufacturers. The basic idea is that if we know how long it takes the truck to apply a gallon of paint, then hold a container under the bead guns and measure the volume of the beads after 10 seconds to get the number of pounds per gallon for glass beads. This can be used to compare with the specified values, 6 
lb/gal or $12 \mathrm{lb} /$ gal for waterborne paints, depending on the type of glass bead used [FHWA 2003].

\section{METHODOLOGY}

The methodology used in this study was to collect field retroreflectivity values with a handheld retroreflectometer and photograph the marking surface using a digital camera. The digital images were analyzed and a bead density value was generated for each pavement marking line. Then, we analyzed the impact of bead density on paint pavement marking retroreflectivity.

\section{Field Data Collection}

We first describe the site selection and layout process. Then, we discuss how we collected marking retroreflectivity data and how we captured glass bead images in the field.

\section{$\underline{\text { Site Selection and Layout }}$}

The paint data were collected on 40 secondary road sites in four highway divisions in NC. The sites were selected randomly on a set of two lane highways. The selected sites were deemed to be typical. These roads generally have low traffic volumes whose annual average daily traffic (AADT) is at or below 4000 vehicles per day. All measured roads were two-lane highways with asphalt pavement surfaces (chip sealed or plant mixed asphalt). The $\mathrm{R}_{\mathrm{L}}$ measurements for each line were collected within a roadway section that was about 10 feet long. The date of marking installation was known for all sites. An example site layout is illustrated in Figure 1.

\section{$\underline{\text { Retroreflectivity Measurement }}$}

The research team used a handheld LTL 2000 retroreflectometer for data collection. This retroreflectometer uses 30-meter geometry, which is the geometry required by ASTM Specification E 1710-05 [ASTM 2005]. The standard operating procedure in the instrument manual was strictly followed during field data collection. Field calibration of the LTL 2000 was conducted at each site prior to the start of data collection.

Three measurements were collected for each white edge marking line in the direction of vehicle travel. For the yellow center lines, three measurements were collected in each direction because a previous study found that centerline retroreflectivity values measured in the direction of paint 
application are significantly higher than the values measured in the opposite direction [Rasdorf et. al. 2009]. Thus, six measurements for each yellow center line were collected. The average of the three measurements for white edge lines and the average of the six measurements for yellow center lines were used as the line retroreflectivity.

\section{$\underline{\text { Image Acquisition }}$}

We photographed five to eight marking images with a digital camera in the same segment of the road as the $R_{L}$ measurements were taken (Figure 1). The glass bead images were obtained using the macro zoom mode of a Canon SD camera. This camera enabled us to collect high-resolution images without a specialized digital image capturing device. Totally, about 1,000 glass bead images were collected over our entire study area of 40 sites. From these we selected 9 sites comprising 108 images. These sites were selected because they contained plant mixed asphalt surfaces rather than bituminous surface treatment pavements.

\section{Bead Density Determination}

Figure 2 shows an example of a good quality glass bead image (a 14 month old marking) collected in the field. One can clearly see that there are three primary elements on all images (as well as all of the other images): glass beads, paint background, and holes (voids) left by the glass beads when they are worn away.

Recall that both the Rich [2002] and Mizera [2009] studies were conducted on newly applied pavement markings. Such new markings do not typically have obvious glass bead loss. Few to no holes appear in them. Figure 3 shows an image of a newly applied pavement marking. Not a single bead is found to be worn away on the marking surface. Intuitively, we speculate that when time and traffic pass by, more glass beads are worn away and more holes are created (resulting in Figure 2, for example). The percentage of glass beads decreases while the percentage of holes increases with time. This is the primary cause of pavement marking retroreflectivity degradation over time - a reduction in bead density.

In the following sections, the manual, automated, and semi-automated methods used to determine glass bead density are presented. 


\section{Counting - A Completely Manual Method}

Mizera's manual counting method provides one way to calculate glass bead density. Using images of a predefined area (such as 2 inches by 2 inches) on the marking surface one can count the number of the beads in the area. If the average bead size (diameter) is known, the total surface area of all glass beads can be estimated. Then, the total area of glass beads is divided by the total marking area to determine the bead density.

The pavement markings in our study area contained Type I glass beads. From Table 1, we can determine that the median diameter of a Type I glass bead is same as the size of a No. 40 Sieve, which is $425 \mu \mathrm{m}$ or $0.0165 \mathrm{inch}$. Thus, the median area of a Type I glass bead is $0.214 \times 10^{-3}$ inch $^{2}$. The mean size is estimated to be $455 \mu \mathrm{m}$ using the gradation of Type I glass beads.

Thus, it is possible to manually determine the bead density of an image (using the above procedure and the estimated median area of a Type I glass bead) by counting the number of visible beads. However, the estimated bead density values using this approach are not accurate. The reason for this is evident by a close inspection of Figure 4 which illustrates three typical cases of glass bead embedment. When more than half of a glass bead is embedded in the paint binding material it is most secure and is least subject to being dislodged. The second and third types of embedment (half of the glass bead, and less than half of the glass bead) result in beads that are much more easily worn off, especially when the markings are exposed to traffic for longer periods of time. Most glass beads that remain in older markings are embedded more than half way. Thus, most images (and most pavement markings) contain more deeply embedded beads only. Clearly, the surface area of a bead embedded this way is actually smaller than the estimated median area outlined in the procedure above because the true area is established by the chord length $\mathrm{C}$ rather than by the bead diameter $\mathrm{D}$ (Figure 4). Thus, $\mathrm{C}<\mathrm{D}$ and the area of type 1 embedment is smaller than the area of types 2 and 3. Thus, the estimated bead densities from the counting method are higher than the actual values. It should be noted that one could convert an estimation of diameter $\mathrm{D}$ to chord length $\mathrm{C}$ by employing an assumption of the average percentage of a bead that is embedded. However, the assumption may be erroneous. Without an assumption of the average percentage of the bead that is embedded, the manual counting method 
can accurately produce a glass bead count (and perhaps an initial density) but not an accurate glass bead density for older pavement markings.

\section{Automated Image Processing}

The ideal solution for determining glass bead density is to find an image segmentation algorithm and use a computer to automatically process the glass bead images. To explore this approach we studied several image segmentation methods including global thresholding, region growth, and marker-controlled watershed segmentation. Unfortunately, we found that none of these methods works reliably and none can produce an accurate estimation of the bead density. We discuss those methods in the following sections.

\section{Global Thresholding}

Thresholding is based on the grayscale histogram of an image. The histogram shows, for each gray level, the number of pixels in the image that have that gray level. Figure 5 shows the grayscale histogram of Figure 2. The x-axis quantifies the gray scale levels which represent pixel intensity. Pixel intensity has 256 levels where level 0 represents black and level 256 represents white. The $y$-axis represents the number of pixels or the frequency of occurrence of a pixel intensity level. Thus, Figure 5 shows that (in Figure 2) there are about 2,500 pixels of intensity level 150 and about 15,000 pixels of intensity level 210 .

An analysis of the Figure 2 image reveals that there are three primarily elements of interest beads, voids, and background. In Figure 5 it is seen that the element with gray level range of approximately 60-120 represents darkness (holes) in the image. The element with a gray level range of approximately 120-170 represents the glass beads. The element with a gray level greater than 170 represents very light grayscale - the background paint. The threshold which separates the holes from the glass beads is somewhere between 110 and 130. The threshold which separate the glass beads from background paint is somewhere between 160 and 180. But where exactly and how can this be determined? There is no clear answer.

Still, if the thresholds were able to be determined this way one could then calculate the hole density and bead density by analyzing the binary images in an automated fashion. The number 
of pixels in any of the three critical areas divided by the total number of pixels would yield the required density.

However, the global thresholding method has serious drawbacks. First, the bead and hole density values are too sensitive to the thresholds. For example, if we select 120 as the threshold separating holes and beads for the image with the histogram shown in Figure 5, a selection of 165,170 , or 175 as the threshold separating beads and backgrounds would result bead density values of $17.4,20.0$, and $22.7 \%$. Thus, a change in threshold value from 165 to 175 results in as much as a 5 to $6 \%$ difference in bead density.

Finally, Figure 5 represents one of the best histograms we obtained. Figure 6 illustrates another valid histogram of our images. The reader can clearly see that discernable break points between beads, voids, and background are not in evidence. Thus, after having processed hundreds of images using this approach it we did not find it to be fruitful.

\section{Region Growth}

Region growing is a procedure that groups pixels or sub-regions into larger regions based on predefined criteria. The basic approach is to start with a set of "seed" points and from these grow regions by appending to each seed those neighboring pixels that have properties similar to the seed [Gonzalez and Woods, 2003]. For the images with histograms similar to Figure 5, the starting points were set to be the pixels with grayscale levels less than a threshold (such as 100 for Figure 5).

The difficulty of the region growth method is twofold - first, what is the threshold and second, what is the formulation of a stopping rule? Both of these problems have to do with finding the cutoff points (boundaries or thresholds) between the beads, voids, and background and neither method enables us to do so satisfactorily.

\section{Marker Controlled Watershed Segmentation}

The watershed segmentation method has been used to find drainage basins and watershed ridge lines in an image by treating the image as a surface where light pixels are at high elevations and 
dark pixels are at low elevations. Watershed segmentation often produces more stable segmentation results than other methods. The concept of watershed segmentation and its algorithms are described in detail by Gonzalez and Woods (2003). Our findings are that directly applying the watershed segmentation method to a glass bead image leads to over-segmentation, which means the image is segmented into too many regions. We did consider an approach used to control segmentation that is based on the concept of a marker [Gonzalez and Woods 2003]. We applied the marker controlled watershed segmentation to our bead images. The glass bead density values produced by the watershed segmentation method were either unreasonably high or low. The method was not considered to be accurate or reliable.

\section{Computer-Aided Counting - A Semi-automated Method}

All of the manual counting and automated image processing methods we investigated or considered failed to satisfactorily generate the desired bead density values for a large range of images. Thus, we considered combining the two methods and created an approach we refer to as computer-aided counting.

Glass beads are generally round in shape. Thus, we can determine the center and the radius of a glass bead by knowing the coordinates of three points in its circumference. If two of the three known points and the center point of the circle are in a line, the center and the radius of the glass bead (circle) can be determined by using only the two points on the circumference.

We developed a bead density analysis program (BDAP) to take this into account. The program requires two mouse clicks to select a glass bead on an image. The positions of the two clicks must be at the two end points of a diameter. If the coordinates of the two mouse clicks are (x1, $y 1)$ and $(x 2, y 2)$, the center of the glass bead then is $((x 1+x 2) / 2,(y 1+y 2) / 2)$ and the diameter of

the glass bead is $\mathrm{D}=\sqrt{\left(x_{1}-x_{2}\right)^{2}+\left(y_{1}-y_{2}\right)^{2}}$. If the entire glass bead is contained within the image (as is Bead 1 in Figure 7) the area of the bead is

$$
\mathrm{A}=\pi \times(D / 2)^{2}
$$

If a small portion of the glass bead is outside of the image (such as Bead 2 in Figure 7), the area of the bead is 


$$
\mathrm{A}=\pi \times(D / 2)^{2}-\alpha(D / 2)^{2}+d(D / 2) \sin \alpha
$$

Where,

$d=$ Distance from the center of the bead to the edge of the image

$\alpha=$ The angle $\arccos (2 d / D)$ in radius

If more than half of a glass bead is outside of the image (such as Bead 3 in Figure 7), the program user needs to imagine the point outside the image (point 2 of Bead 3 in Figure 7). Then, the area of the bead is calculated as:

$$
\mathrm{A}=\alpha(D / 2)^{2}-d(D / 2) \sin \alpha
$$

Where the $\mathrm{D}$ and $\alpha$ have the same meaning as in the previous equation.

The overall area of an image is calculated by multiplying the image width and image height. The area of the beads is the sum of the areas of each glass bead. The bead density is then obtained by dividing the total bead area by the overall area of the image.

The flowchart for the computer aided counting method algorithm of the program is shown in Figure 8. The first steps include loading the image, calculating the image size, and enlarging the image according to a user input ratio that supports good visualization. The user can then select a bead with two mouse clicks. The program calculates the bead area and updates variables representing the total area of beads (BeadArea) and the number of beads counted (BeadNum). The beads are selected one by one until they have all been measured. The program outputs the cumulative bead density and the number of beads contained within the image. The program could also be used to determine hole density and the number of the holes in the image.

Figure 9 illustrates the bead selection process described by the algorithm. When a bead is selected (two mouse clicks), the program graphically circles and numbers the bead. Figure 9 shows that 15 beads have been selected so far. The total area of selected glass beads is 7,208 image pixels. The total area of the image is $480,000(800 \times 600)$ pixels. The calculated bead density for these 15 beads is $1.9 \%$. The selecting process should continue until the last bead is selected and all beads are cumulatively tallied.

The computer-aided counting method works well on the field collected images. Because it is (regrettably) only a partially automated method, about 10 minutes are needed to analyze each 
image. While not ideal this is not unreasonable given the value of the results that can be obtained.

\section{RESULTS}

It is important to note that the quality of the images collected from plant mixed asphalt pavement is much better than the images from chip sealed pavement. Images from 9 sites (with markings applied on plant mixed asphalt pavement) were processed. Each site has four marking lines. We processed three images for each line resulting in a total of 108 images processed.

The three bead density values for each pavement marking line were averaged to determine the bead density for the marking line. Doing so accounted for keep variations in point density values. Table 2 shows the bead density and retroreflectivity values at one measurement location (Site 11). The values in the column titled "Line Density" and the column titled "Line $\mathrm{R}_{\mathrm{L}}$ " are used in the correlation analysis.

The normal range of bead density we observed was 9-24 percent of the paint marking surface. The bead density values of only five marking lines were out of this range (out of 36 lines measured). Two yellow center marking lines have bead density values of $3.0 \%$ and $3.3 \%$. These two marking lines were from the same road. Figure 10 (a) shows one of the images from the two marking lines. It is clear from the image that, for whatever reason, the majority of the beads were gone.

Three white edge markings had bead density values of $26.1 \%, 27.9 \%$, and $30.7 \%$. The glass beads on those roads are especially dense. Figure 10 (b) shows one of the images from the marking lines with a bead density of $30.7 \%$.

The $9-24 \%$ bead density range is comparable to Rich's research results [Rich et. al. 2002]. Rich's study measured three paint sample sites and the approximate bead densities of these paint markings were 8,18 , and $20 \%$. The $18 \%$ and $20 \%$ bead densities are in the range of $9-24 \%$. A bead density of $8 \%$ is very close to this range. 
Figure 11 clearly shows that bead density values have a positive correlation with the marking retroreflectivity readings. The linear regression equations for the white edge markings and yellow center markings are:

$$
\begin{array}{ll}
\mathrm{R}_{\mathrm{L}}(\text { white })=90.0+9.50 \times \text { Density } & \left(\mathrm{R}^{2}=0.73\right) \\
\mathrm{R}_{\mathrm{L}}(\text { yellow })=52.7+6.11 \times \text { Density } & \left(\mathrm{R}^{2}=0.61\right)
\end{array}
$$

Where:

$$
\begin{aligned}
& \mathrm{R}_{\mathrm{L}} \quad=\text { Retroreflectivity of pavement markings in } \mathrm{mcd} / \mathrm{m} 2 / \mathrm{lux} \\
& \text { Density }=\text { Bead density in percentage }
\end{aligned}
$$

The values of 9.50 and 6.11 are the slopes of the regression lines. The positive signs of the two values indicate that retroreflectivity readings increase as bead density increases. The coefficient of determination, $\mathrm{R}^{2}$, is the proportion of the variability in the response explained by the regression model, which can be used to determine how well the regression line approximates the real data. The $\mathrm{R}^{2}$ values of 0.73 and 0.61 for white edge lines and yellow center lines indicate the regression lines fit the data reasonable well. We also fitted the data using a quadratic curve and found the result was slightly better. Give the small sample size of the study (18 points for each type of markings), a linear regression fit is considered to be satisfactory.

Notice also that the regression line for white edge markings is significantly higher than the regression line for yellow center markings. Thus, white edge markings have higher retroreflectivity values than yellow markings when the bead density values are same. For example, when the bead density is $15 \%$, white markings have a retroreflectivity value of 233 $\mathrm{mcd} / \mathrm{m}^{2} / \mathrm{lux}$ while yellow markings have retroreflectivity value of $144 \mathrm{mcd} / \mathrm{m}^{2} / \mathrm{lux}$. This is approximately $60 \%$ more $\mathrm{R}_{\mathrm{L}}$ for white lines. This research result is consistent with the findings of a previous study by Craig et. al [2007] showing that white edge lines generally have higher retroreflectivity values than yellow center lines.

Table 3 summarizes the relationship between bead density and retroreflectivity. If a bead density value is in the range of $9-15 \%$, white edge lines and yellow centerline markings have retroreflectivity values between $175-232 \mathrm{mcd} / \mathrm{m}^{2} / \mathrm{lux}$ and $107-144 \mathrm{mcd} / \mathrm{m}^{2} / \mathrm{lux}$, respectively. 
The FHWA and other transportation agencies are working together to establish a minimum retroreflectivity standard for pavement markings. A recent FHWA publication proposed recommendations for the minimum levels of pavement marking retroreflectivity which were based on the results of a Target Visibility Predictor (TARVIP) computer model [FHWA 2007]. If the paint truck speed is in the ranges of less than $50 \mathrm{mi} / \mathrm{hr}, 50-70 \mathrm{mi} / \mathrm{hr}$, or greater than 70 $\mathrm{mi} / \mathrm{hr}$, the recommended minimums are 40,60 , or $90 \mathrm{mcd} / \mathrm{m}^{2} / \mathrm{lux}$ for fully marked roadways (with edge lines) where retroreflected raised pavement markers (RRPMs) are not provided. Our study shows that for pavement markings with a $10 \%$ bead density, white edge lines and yellow center lines have predicted retroreflectivity values of $185 \mathrm{mcd} / \mathrm{m}^{2} / \mathrm{lux}$ and $114 \mathrm{mcd} / \mathrm{m}^{2} / \mathrm{lux}$ respectively. Generally speaking, this is more than enough retroreflectivity for drivers and it is well above the recommended minimum.

\section{CONCLUSIONS}

The image processing techniques we studied did not satisfactory enable us to determine bead density. The bead density results from the complete manual counting method tend to be higher than the actual values. None of the three automated methods (global thresholding, region growth, and marker control watershed segmentation) yielded reliable and satisfactory bead densities for the field collected images.

However, we did find a semi-automated compromise that can satisfactorily be used to obtain bead density values from paint pavement marking images. The method is easy to use and has a relatively low cost. Most importantly, it is quite accurate. The bead density values obtained from multiple tests of the same image are normally very close to each other (typically within a range of $\pm 1 \%$ ). The method can also be applied to other types of markings.

Our findings clearly indicate that glass bead density has a significant impact on marking retroreflectivity. Higher glass bead density leads to higher marking retroreflectivity. Furthermore, white edge markings have conclusively higher retroreflectivity values than do yellow center markings when the bead density values are the same. 
The bead density values in the tested NC pavement markings are most normally in the range of 9-24 percent of the paint marking surface. Markings with bead density values lower than $9 \%$ are considered to have too few glass beads on the marking surface to provide acceptable retroreflectivity. This knowledge could be used by state DOTs to select a suitable and desirable bead density and then monitor the glass bead application process to ensure the achievement of the desired density.

\section{RECOMMENDATIONS}

It is recommended that a similar study be conducted for other types of pavement markings, especially thermoplastics. This study focused on paints because they comprise the majority of markings. Additionally, the traffic control required for data collection was much easier on twolane highways than on other types of highways. Other types of pavement markings are expected to have a similar correlation between retroreflectivity and bead density values, but the regression lines are expected to have different intercepts and slopes.

A similar study on different types of pavement surface materials (such as chip sealed asphalt surface, concrete pavement) is also recommended. A study should also be conducted in different climate zones, especially in a northern area where weather and temperature are more severe than in NC.

This study was conducted on two-lane highways with low traffic volumes. A similar study could be initiated to evaluate bead density differences on high traffic volume roads. We also recommend conducting a similar study using larger glass beads. Such a study could evaluate whether markings with large glass beads provide better retroreflectivity than markings with standard glass beads if the bead densities are same.

The retroreflectivity values have an obvious variation when the bead density is in the range of 10-15 percent as indicated in Figure 11 especially for white edge lines. The colors of the markings are observed to vary for both white edge and yellow center markings. The marking color (within white or within yellow) is speculated to be another factor with a significant impact 
on marking retroreflectivity. Thus, we recommend conducting a chromatography study to determine whether or not marking color plays a role in determining marking retroreflectivity.

Finally, it would be interesting to study how the bead density values change over time. Our images showed that some old markings have a high hole density. It would be possible to determine when the holes are formed (the glass beads are worn away) if we know the marking bead density values over time. By conducting such a study, we could know more about the physical process of pavement marking retroreflectivity degradation over time. Thus, we could determine an optimal initial bead density range for new paint striping in order to achieve good $R_{L}$ performance for the whole life cycle of paint markings.

\section{ACKNOWLEDGEMENT}

The authors acknowledge the sponsorship of this research by the NCDOT. The authors would especially like to thank Mr. Chris Howard, Ms. Meredith McDiarmid, and Mr. Mark Manriquez of the NCDOT for their support during this study. Still, the contents of this paper reflect the views of the authors, who are responsible for the data and results presented herein, and do not necessarily reflect the views of the NCDOT. 


\section{RERERENCES}

American Association of State Highway and Transportation Officials (AASHTO) (2004). A

Policy on Geometric Design of Highways and Streets 5th Ed, AASHTO, Washington D. C., Pages 294-295.

American Association of State Highway and Transportation Officials (AASHTO) (2007). Standard Specification for Glass Beads Used in Traffic Paint. AASHTO, Washington D. C.

Abboud, N. and Bowman, B. L. (2002). "Cost and Longevity-Based Scheduling of Paint and Thermoplastic Striping.” Transportation Research Record, Volume 1794, Pages 55-62.

American Society for Testing Materials (ASTM) (2001). "Standard Practice for Describing Retroreflection." ASTM E 808, American Society for Testing Materials International, West Conshohoken, PA.

American Society for Testing Materials (ASTM) (2005). "Standard Test Method for Measurement of Retroreflective Pavement Marking Materials with CEN-Prescribed Geometry Using a Portable Retroreflectometer." ASTM E 1710-05, American Society for Testing Materials International, West Conshohoken, PA.

Andrady, A L. (1997). Pavement Marking Materials: Assessing Environment-Friendly Performance, NCHRP Report 392. Transportation Research Board, Washington, D. C.

Craig, W. N., Sitzabee, W. E., Hummer, J. E., and Rasdorf, W. (2007). "Impact of Line Location on Pavement Marking Retroreflectivity Degradation." Journal of Public Works Management and Policy, Volume 12, Number 2, Pages 431-450.

Dale, J. M. (1998). Pavement Markings: Materials and Application for Extended Service Life, NCHRP Synthesis 138. Transportation Research Board, Washington, D. C.

Federal Highway Administration (FHWAb) (2003). Standard Specifications for Construction of Roads and Bridges on Federal Highway Projects, United States Department of Transportation, Washington D. C., Section 634.

Federal Highway Administration (FHWA) (2007). Updates to Research on Recommended Minimum Levels for Pavement Marking Retroreflectivity to Meet Driver Night Visibility Needs, United States Department of Transportation, Washington D. C. 
Gonzalez, R. C, Woods, R. E., and Eddins, S. L. (2003). Digital Image Processing Using Matlab, Prentice Hall, Inc., Upper Saddle River, NJ, USA.

Lee, J., Maleck, T. L., and Taylor, W. C. (1999). "Pavement Marking Material Study in Michigan." Institute of Transportation Engineers (ITE) Journal, Volume 69, No. 7, Pages 44-50.

Migletz, J. and Graham, J. (2002). Long-term Pavement Marking Practices, NCHRP Synthesis 306, Transportation Research Board, Washington D.C.

Mizera, C., Smadi, O., Hawkins, N., and Zitterich, W. (2009). "Pavement Marking Application:

A Bead Gun Evaluation Study Using a High-Speed Camera." Transportation Research Board, TRB Annual Meeting 2009 (DVD-ROM), TRB Paper Number 09-2540.

North Carolina Department of Transportation (NCDOT) (2006). Standard Specifications for Roads and Structures, NCDOT Report, Raleigh, NC.

North Carolina Department of Transportation (NCDOT) (2008). Pavement Marking Rodeo Certification Study Guide, Work Zone Traffic Control Unit, NCDOT, Raleigh, NC.

Perrin, J. Jr., Martin, P. T., and Hansen, B. G. (1998). “A Comparative Analysis of Pavement Marking Materials." Transportation Research Board Annual Meeting 1998 (CD-ROM), TRB Paper Number 98-130.

Rasdorf, W., Zhang, G., and Hummer, J. (2008). "The Impact of Directionality on Paint Pavement Marking Retroreflectivity." Public Works Management and Policy, Volume 13, Number 3, Pages 265-277.

Rich, M. J., Maki, R. E., Morena, J. (2002) "Development of a Pavement Marking Management System," Transportation Research Record, Transportation Research Board, Washington D. C., Volume 1794, Pages 49-54.

Sarasua, W. A., Clarke, D. B., and Davis, W. J. (2003). "Evaluation of Interstate Pavement Marking Retroreflectivity," Report to South Carolina Department of Transportation, Report Number FHWA-SC-03-01.

Sitzabee, W., Hummer, J., and Rasdorf, W. (2009). "Pavement Marking Degradation Modeling and Analysis," Journal of Infrastructure Systems, American Society of Civil Engineers, Volume 15, Number 3, Pages 190-199. 
Virginia Department of Transportation (VDOT) (2008). 2008 Pavement Marking Certification Study Guide, VDOT, Richmond, VA. 


\section{List of Figure Captions}

Figure 1. Field Data Collection Site Layout

Figure 2. A Typical Glass Bead Image

Figure 3. A Newly Applied Paint Pavement Marking Image

Figure 4. Glass Bead Embedment Scenarios

Figure 5. Histogram of the Grayscale Image of Figure 2

Figure 6. Randomly Selected Histogram

Figure 7. Glass Bead Area Calculation

Figure 8. Computer Aided Counting Method Algorithm

Figure 9. Computer Aided Counting Process

Figure 10. Marking Images with Very Low and Very High Bead Densities

Figure 11. Bead Density and Retroreflectivity Relationship 


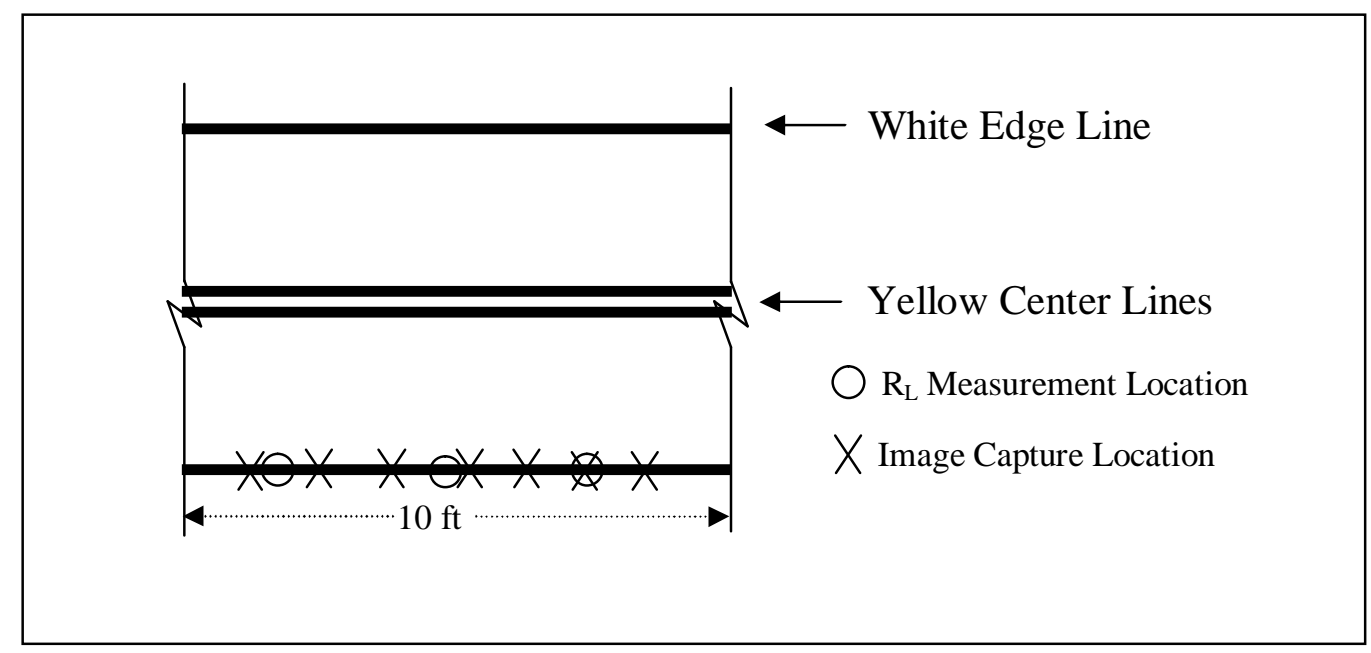

Figure 1. Field Data Collection Site Layout 


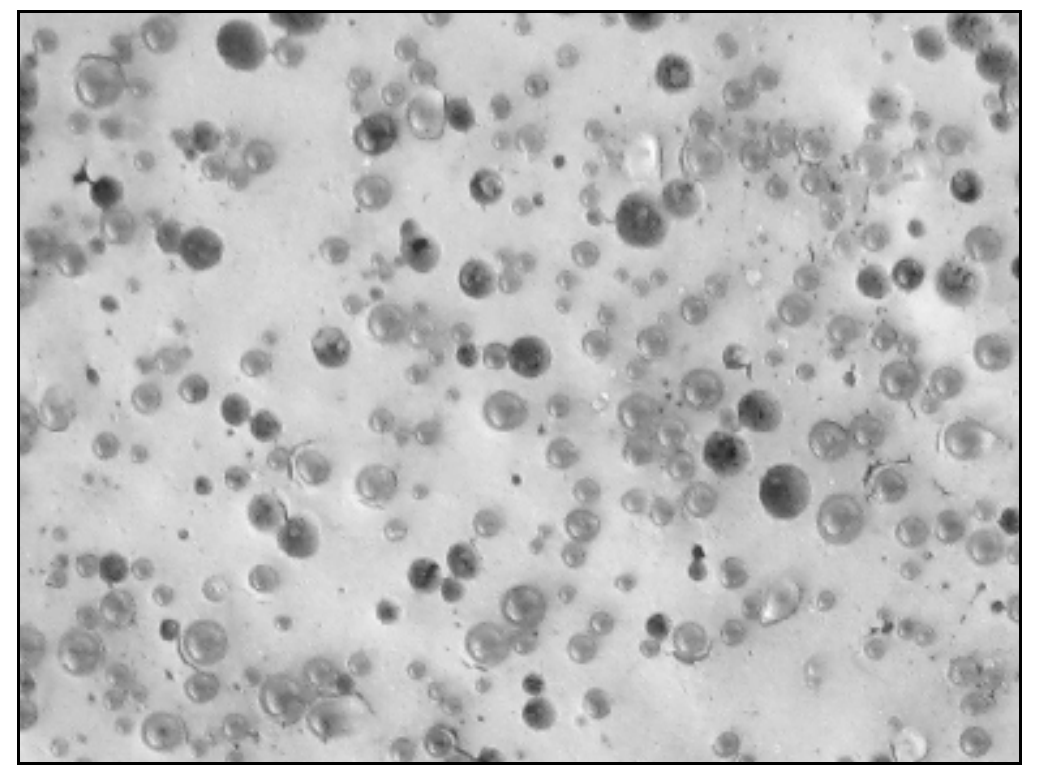

Figure 2. A Typical Glass Bead Image 


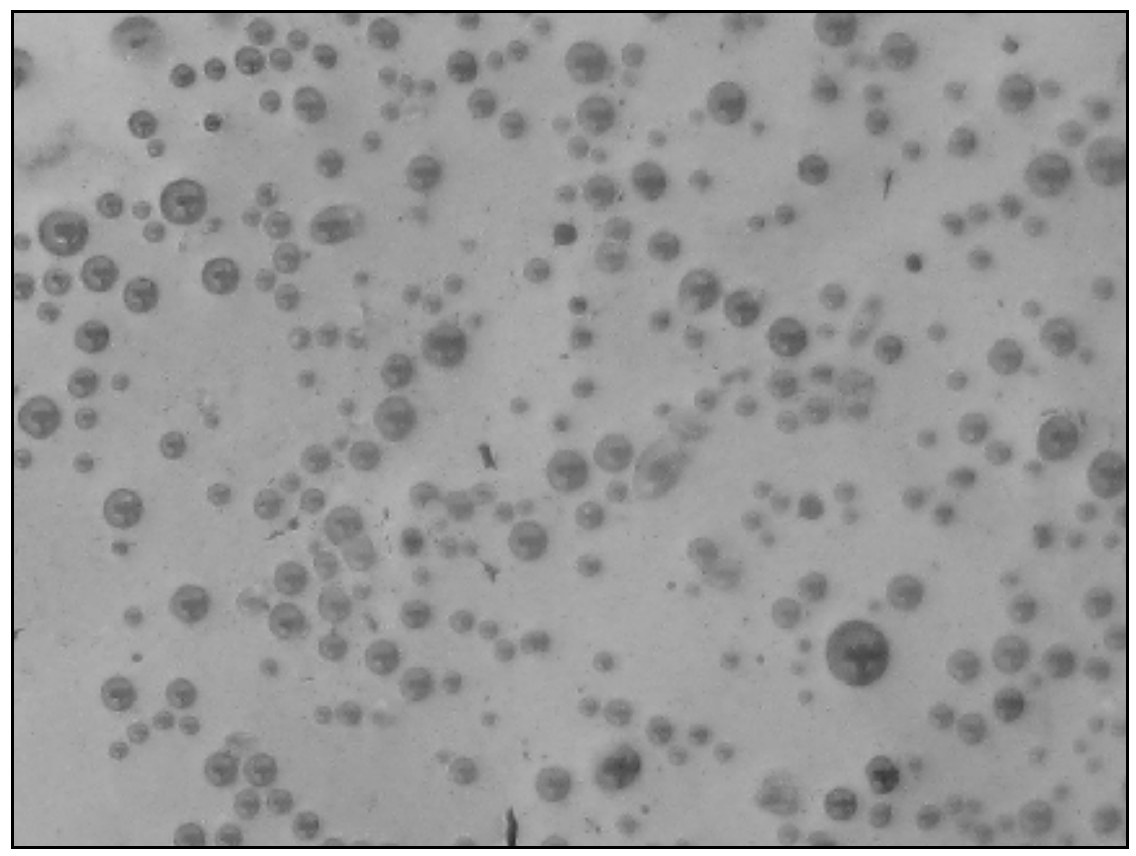

Figure 3. A Newly Applied Paint Pavement Marking Image 


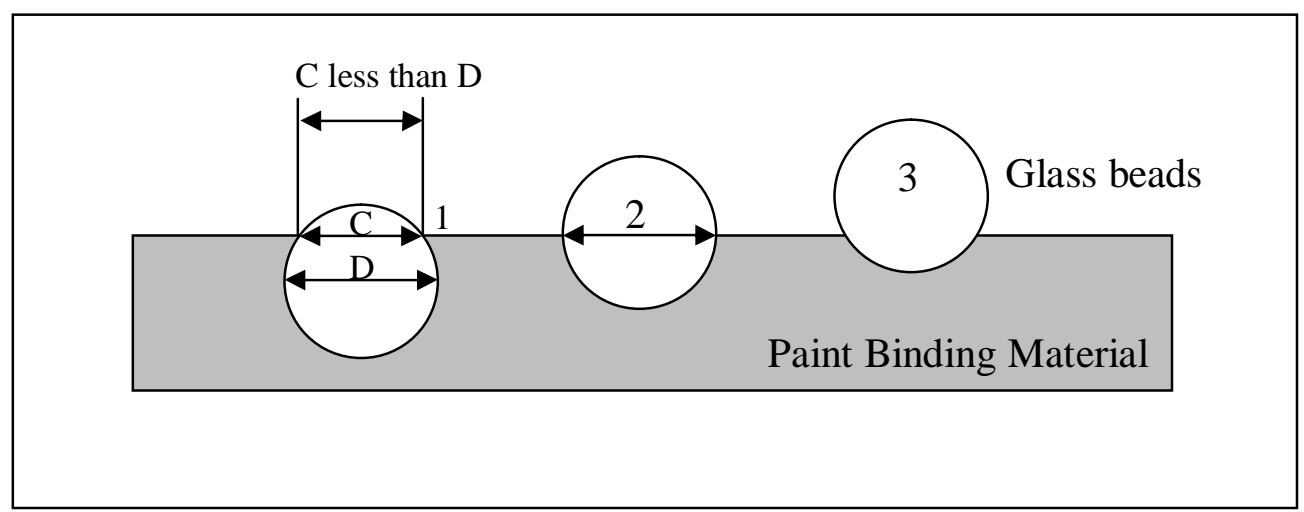

Figure 4. Glass Bead Embedment Scenarios 


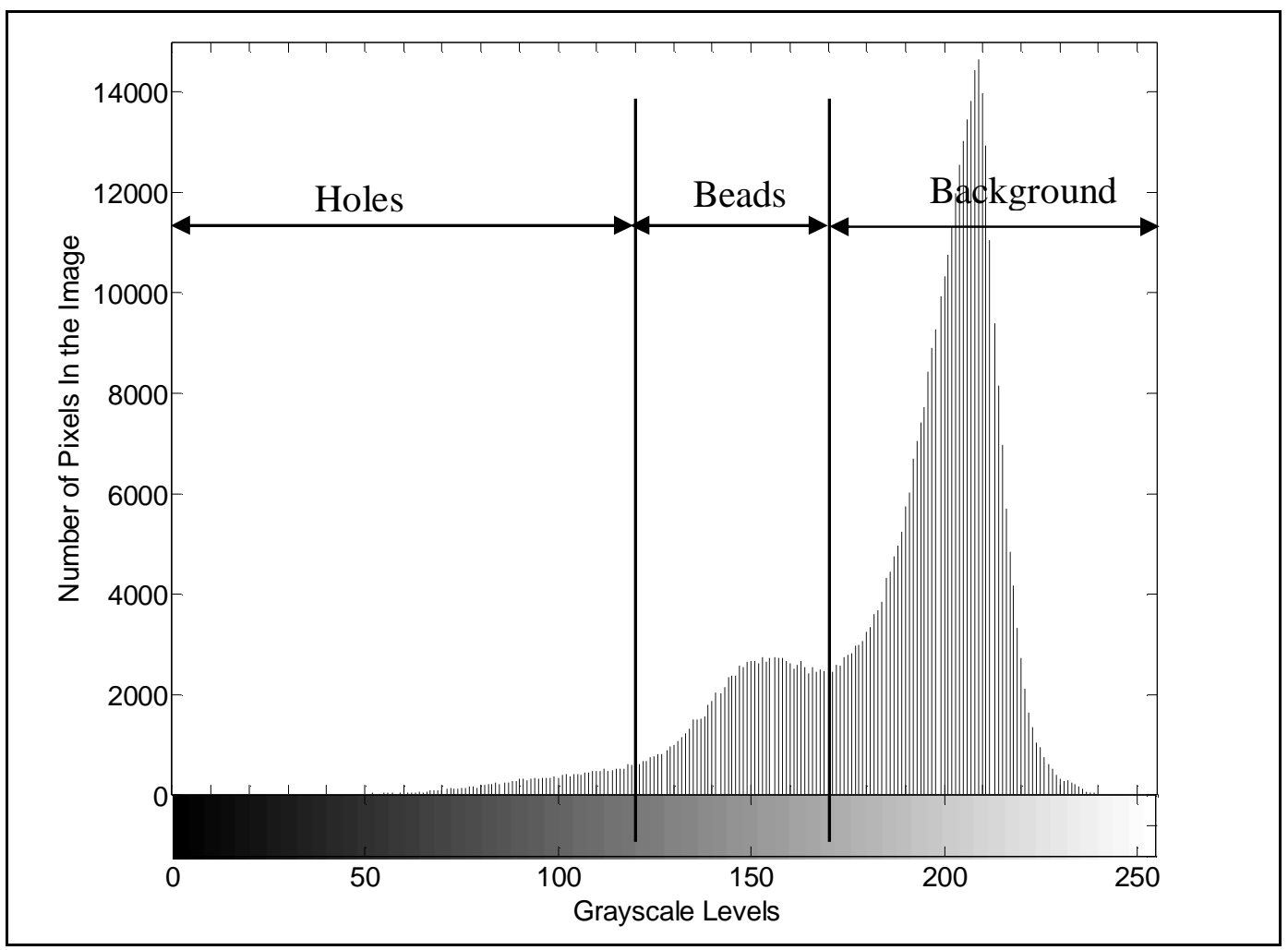

Figure 5. Histogram of the Grayscale Image of Figure 2 


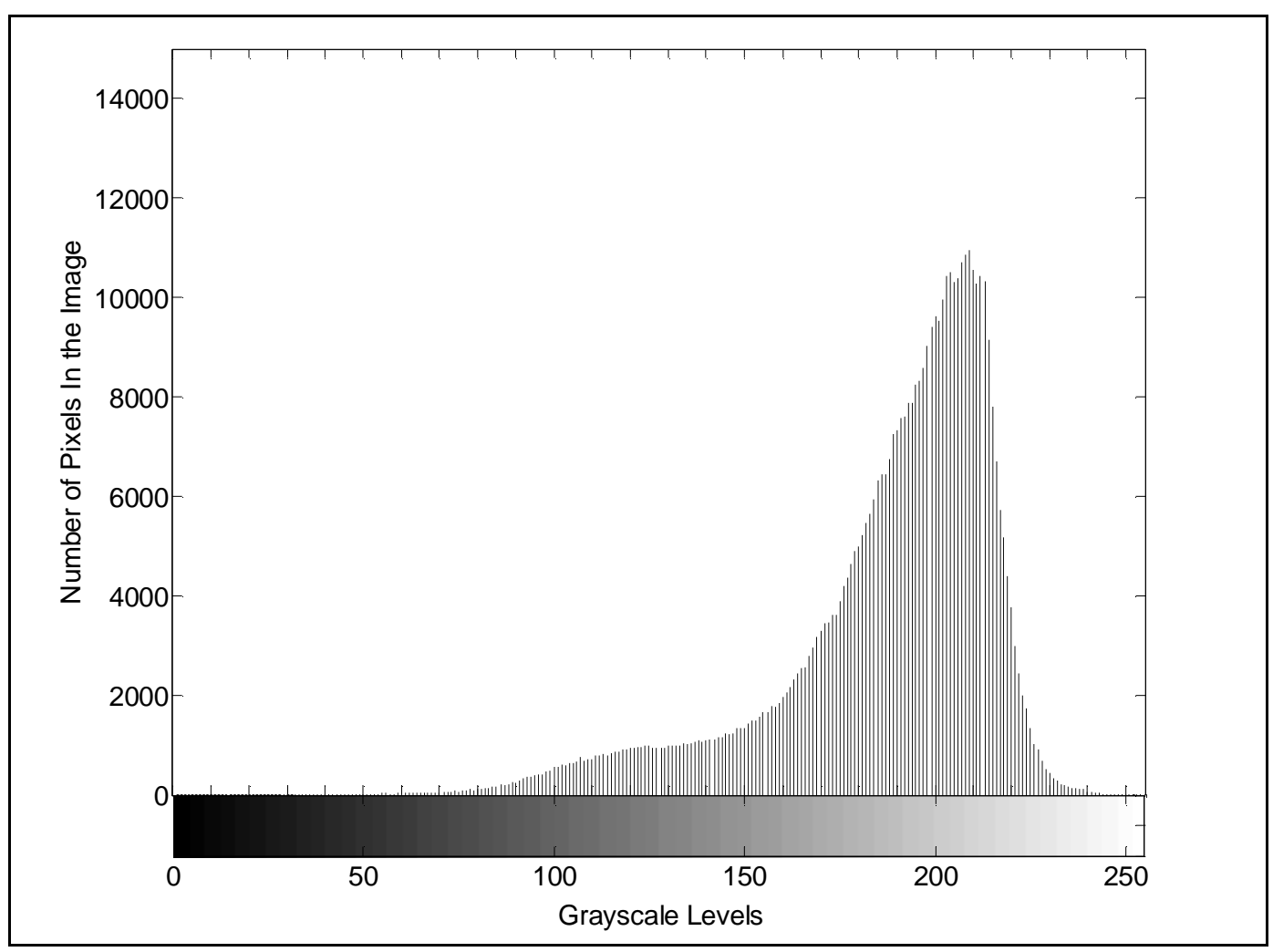

Figure 6. Randomly Selected Histogram 


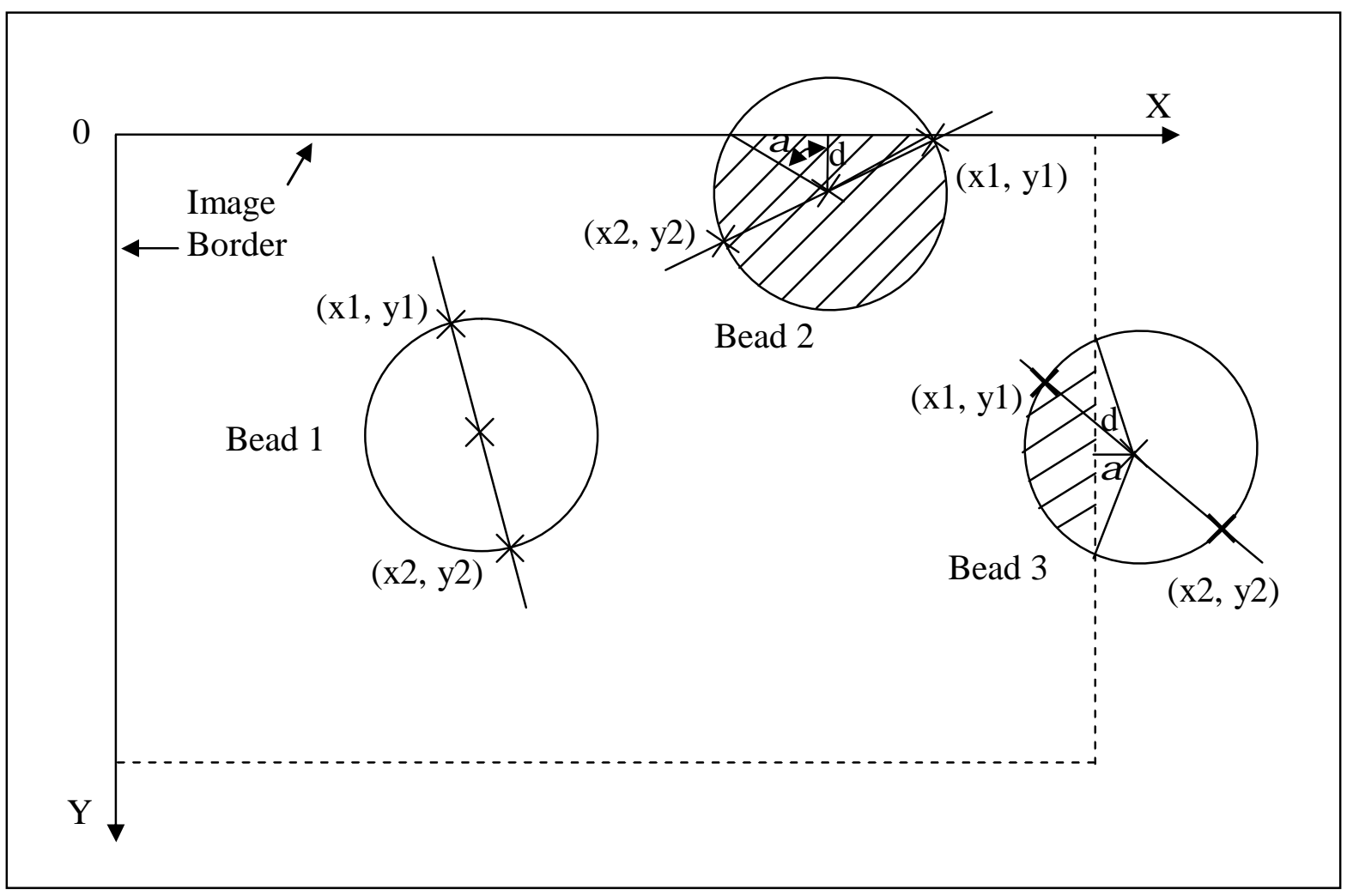

Figure 7. Glass Bead Area Calculation 


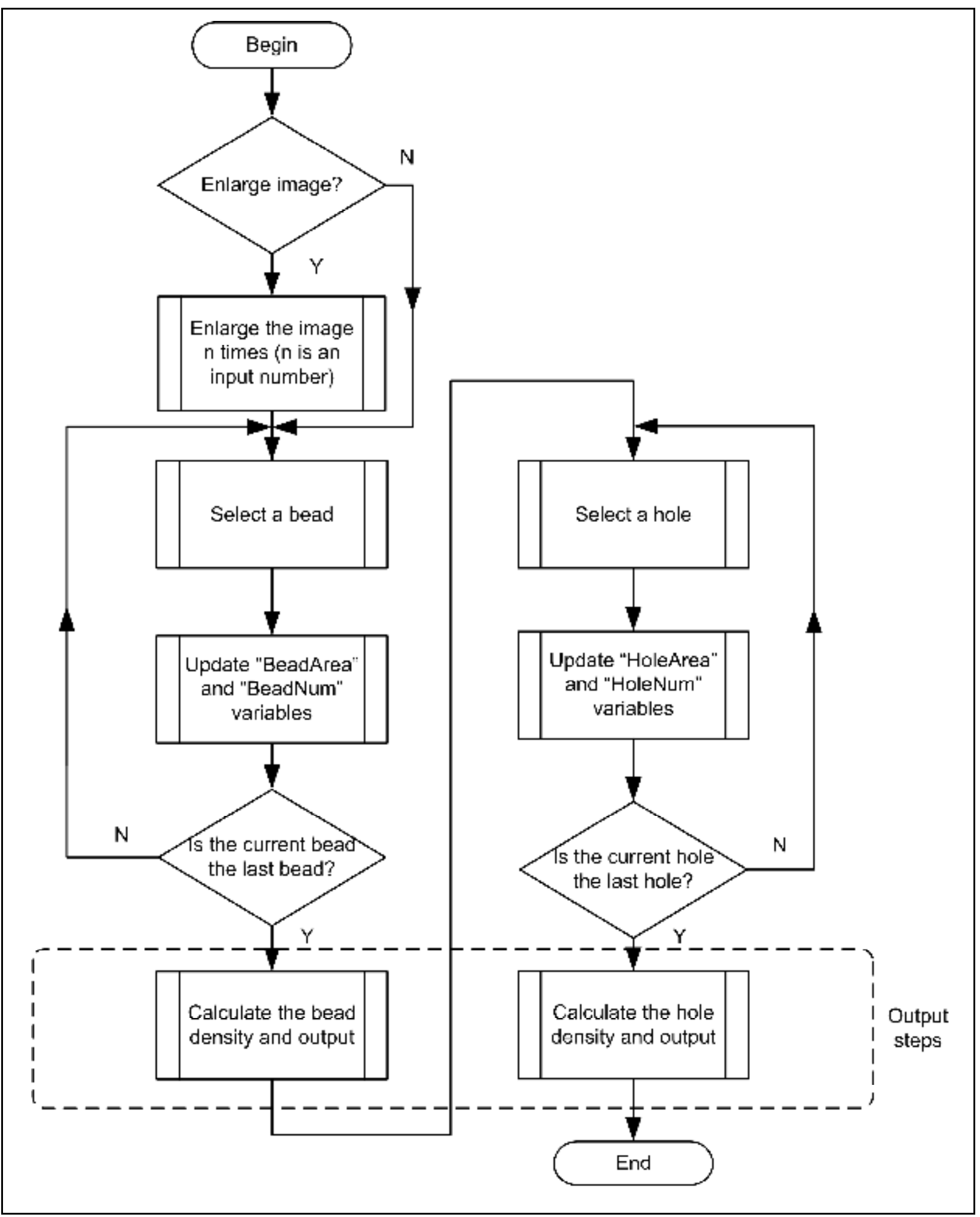

Figure 8. Computer Aided Counting Method Algorithm 


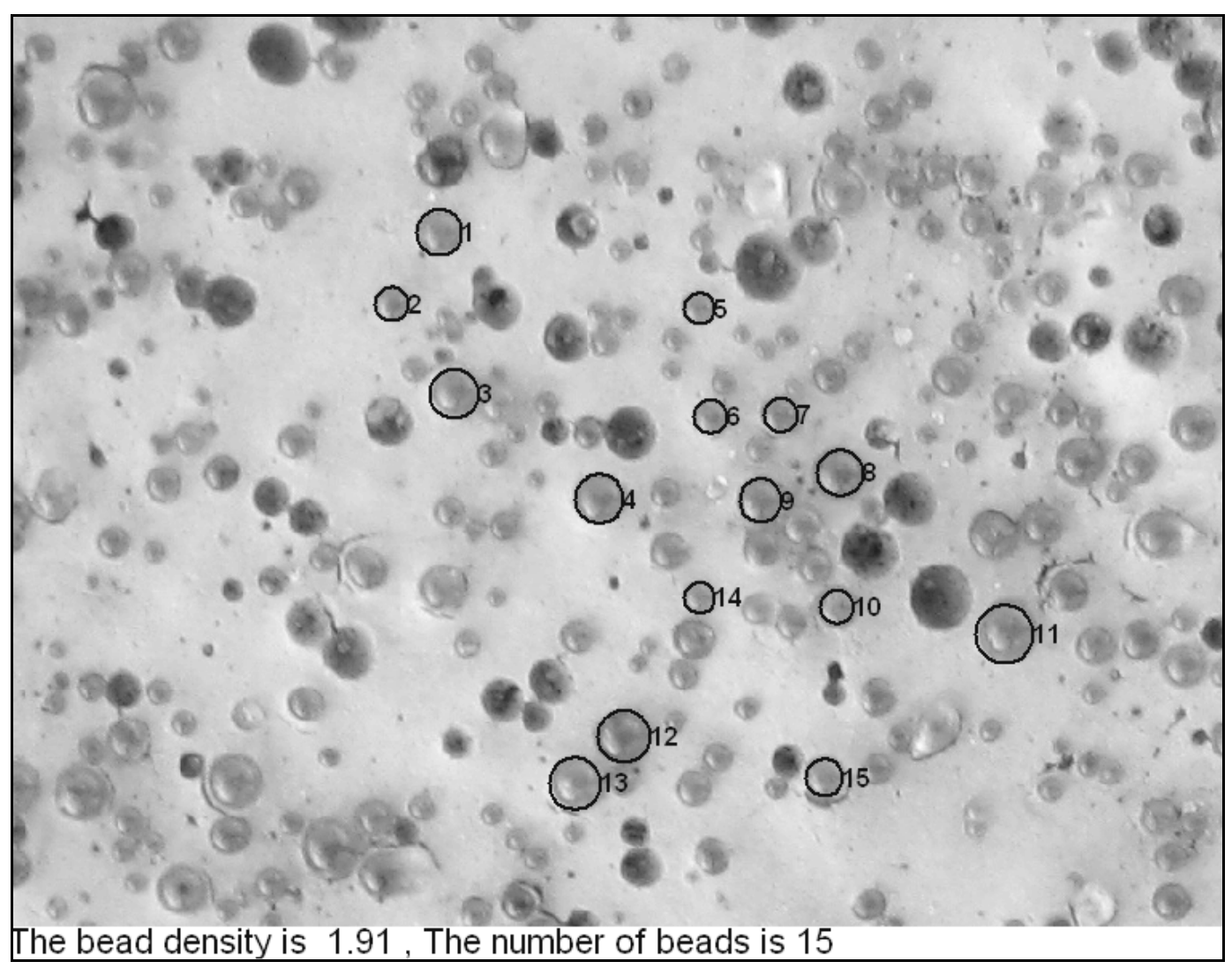

Figure 9. Computer Aided Counting Process 


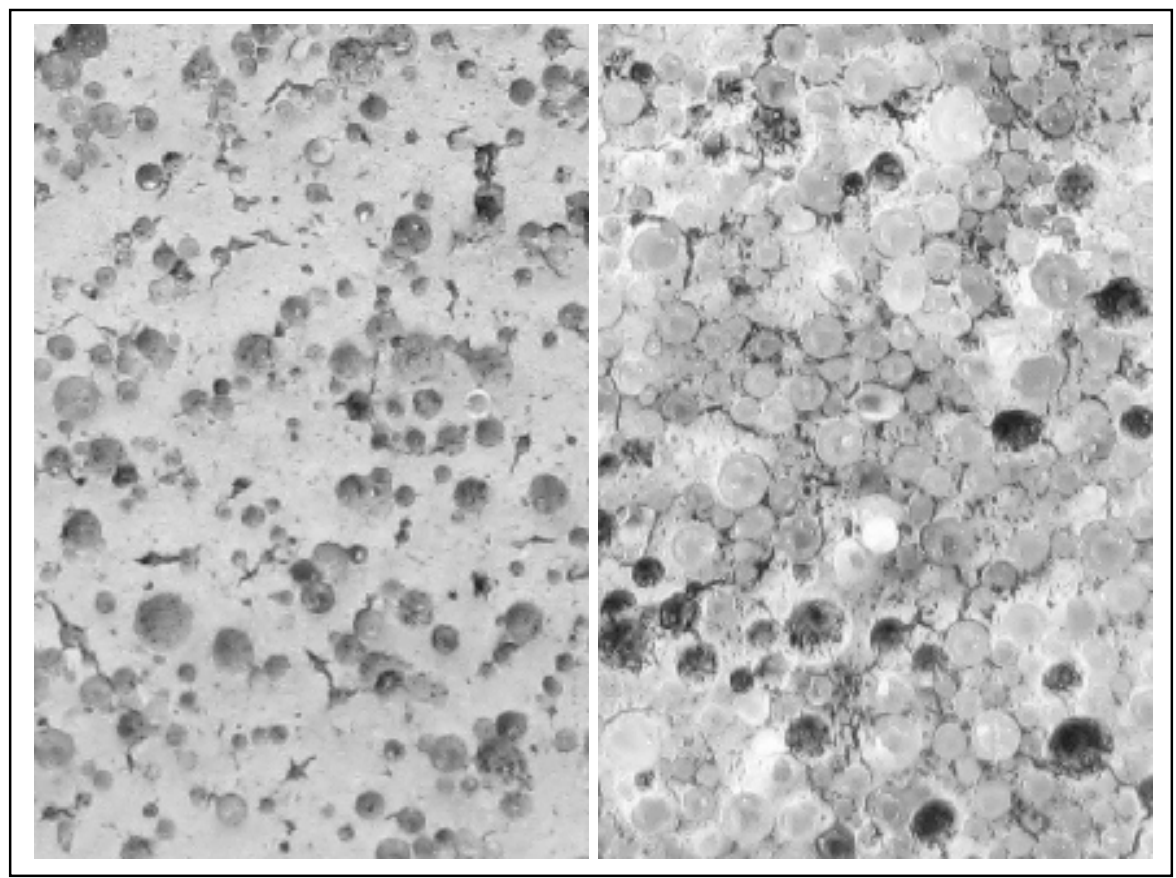

(a)

(b)

Figure 10. Marking Images with Very Low and Very High Bead Densities 


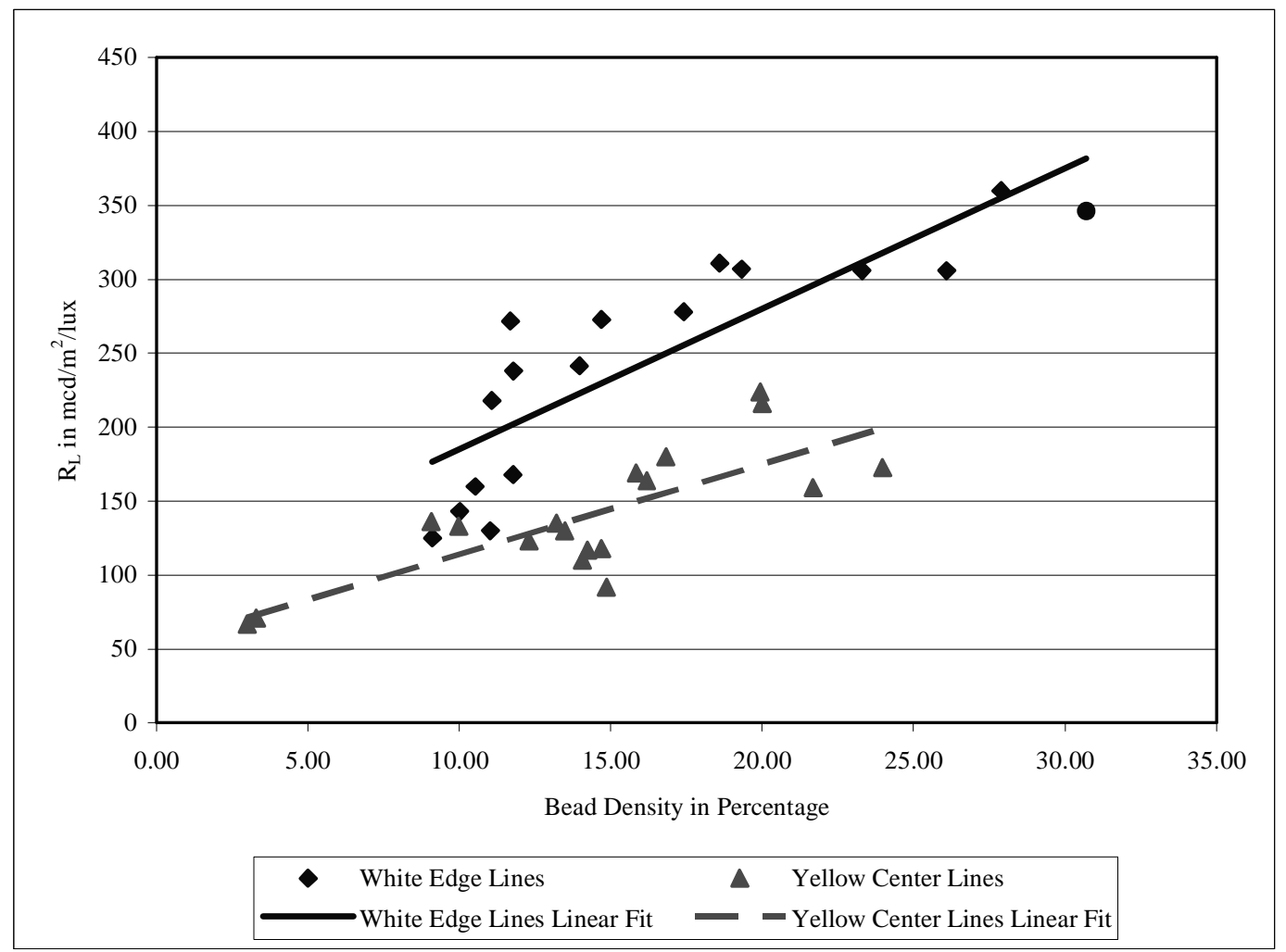

Figure 11. Bead Density and Retroreflectivity Relationship 
Table 1. Gradations of Type I and Type II Glass Beads [AASHTO 2007]

\begin{tabular}{||c||c||c||c|c||}
\hline \multirow{2}{*}{ Sieve Size } & \multirow{2}{*}{$\begin{array}{c}\text { Sieve Size } \\
\text { in } \boldsymbol{\mu m}^{\mathbf{a}}\end{array}$} & \multirow{2}{*}{$\begin{array}{l}\text { Sieve Size } \\
\text { in Inches }\end{array}$} & \multicolumn{2}{c||}{ Mass Percent Passing } \\
\cline { 4 - 5 } & Type I & Type II \\
\hline \hline No. 16 & 1180 & 0.0469 & 100 & - \\
\hline No. 20 & 850 & 0.0331 & $95-100$ & - \\
\hline No. 30 & 600 & 0.0234 & $75-95$ & 100 \\
\hline No. 40 & 425 & 0.0165 & - & $90-100$ \\
\hline No. 50 & 300 & 0.0117 & $15-35$ & $50-75$ \\
\hline No. 80 & 180 & 0.0070 & - & $0-5$ \\
\hline No. 100 & 150 & 0.0059 & $0-5$ & - \\
\hline
\end{tabular}

Note: a $1000 \mu \mathrm{m}=1 \mathrm{~mm}$ 
Table 2. Bead Density and Retroreflectivity Values at Site $\mathbf{1 1}$

\begin{tabular}{|c|c|c|c|c|c|c|}
\hline \multirow{2}{*}{ Image Name } & \multirow{2}{*}{ Color } & \multicolumn{2}{|c|}{ Bead Density in Percentage } & \multicolumn{3}{|c|}{$R_{L}$ in $\mathrm{mcd} / \mathrm{m} 2 / \mathrm{lux}$} \\
\hline & & Point Density & Line Density & Poir & $\mathbf{R}_{\mathbf{L}}$ & Line $\mathbf{R}_{\mathbf{L}}$ \\
\hline No11-SR1613-03.JPG & White & 16.9 & \multirow{3}{*}{18.6} & & & \multirow{3}{*}{311} \\
\hline No11-SR1613-04.JPG & White & 19.6 & & & & \\
\hline No11-SR1613-06.JPG & White & 19.3 & & & & \\
\hline No11-SR1613-10.JPG & Yellow & 14.3 & \multirow{3}{*}{14.7} & 122 & 97 & \multirow{3}{*}{118} \\
\hline No11-SR1613-11.JPG & Yellow & 15.6 & & 132 & 102 & \\
\hline No11-SR1613-12.JPG & Yellow & 14.3 & & 149 & 107 & \\
\hline No11-SR1613-19.JPG & Yellow & 14.2 & \multirow{3}{*}{13.5} & 122 & 98 & \multirow{3}{*}{110} \\
\hline No11-SR1613-20.JPG & Yellow & 13.9 & & 134 & 85 & \\
\hline No11-SR1613-21.JPG & Yellow & 12.4 & & 126 & 96 & \\
\hline No11-SR1613-28.JPG & White & 14.9 & \multirow{3}{*}{14.7} & 26 & & \multirow{3}{*}{273} \\
\hline No11-SR1613-29.JPG & White & 14.7 & & 26 & & \\
\hline No11-SR1613-30.JPG & White & 14.5 & & & & \\
\hline
\end{tabular}


Table 3. Bead Densities and Retroreflectivity Values

\begin{tabular}{||c||c|c||}
\hline $\begin{array}{c}\text { Bead Density } \\
\text { in Percent }\end{array}$ & $\begin{array}{c}\text { White Edge } \\
\text { Line } \mathbf{R}_{\mathbf{L}}\end{array}$ & $\begin{array}{c}\text { Yellow Center } \\
\text { Line } \mathbf{R}_{\mathbf{L}}\end{array}$ \\
\hline \hline$<9$ & $<175$ & $<107$ \\
\hline $9-15$ & $175-232$ & $107-144$ \\
\hline $15-20$ & $232-280$ & $144-174$ \\
\hline $20-25$ & $280-327$ & $174-205$ \\
\hline$>25$ & $>327$ & $>205$ \\
\hline
\end{tabular}

